HISTORIA

\title{
Notas sobre el inicio de la epidemia de tuberculosis pulmonar en Bogotá (1870-1920)
}

\author{
Alvaro Javier Idrovo \\ Departamento de Salud Pública y Tropical, Facultad de Medicina, Universidad Nacional de Colombia, \\ Bogotá, D. C., Colombia.
}

\begin{abstract}
La tuberculosis existió en Bogotá desde la época prehispánica. La ocurrencia durante este período y durante la Conquista y la Colonia fue baja. A finales del siglo XIX y comienzos del XX, la incidencia empezó a aumentar rápidamente hasta conformar una epidemia. En las décadas siguientes, la alta ocurrencia llegó a configurar una endemia de carácter local y nacional. El presente artículo describe y analiza la ocurrencia de tuberculosis pulmonar durante los años 1870 a 1920, así como algunos hechos históricos y características de la sociedad bogotana de finales del siglo XIX, que pudieron favorecer el inicio de esta epidemia en Bogotá. Se resalta el papel protagónico de la anatomía patológica iniciada en la Universidad Nacional en el descubrimiento de la epidemia, la diferenciación entre las lesiones ocasionadas por la tuberculosis y Oesophagostomum radiatum y en la definición de políticas sanitarias. Los hechos descritos indican que el inicio de la epidemia de tuberculosis pulmonar se encuentra íntimamente relacionado con el proceso acelerado de urbanización en Bogotá.
\end{abstract}

Palabras clave: tuberculosis, historia, urbanización, anatomía patológica, epidemiología histórica.

\begin{abstract}
Notes on the onset of a pulmonary tuberculosis epidemic in Bogotá (1870-1920)
Tuberculosis has existed in Bogotá since prehispanic times. The occurrence during this period and during the Conquest and the Colony periods was low. Between 1870 and 1920 the incidence increased to epidemic proportions, in local areas and nationally. The occurrence of pulmonary tuberculosis during this period is described and analyzed; some historic facts and features of society potentially associated with the epidemic are included. The development of pathological anatomy at the Universidad Nacional helped to detect the epidemic, because the differentiation of tuberculosis from Oesophagostomum radiatum lesions became possible, as well as the recommendation of sanitary policies. The pulmonary tuberculosis epidemic was probably associated with the accelerated urbanization that was occurring in Bogotá at the time.
\end{abstract}

Key words: tuberculosis, history, urbanization, pathological anatomy, historical epidemiology.

Las epidemias son eventos importantes en la historia de un pueblo que se sitúan por encima de la ocurrencia habitual de enfermedades en una población y hacen su aparición debido a múltiples factores sociales, económicos y ecológicos. Como consecuencia de las epidemias, los profesionales de las áreas de la salud y las sociedades en general pueden tener

Correspondencia:

Facultad de Medicina, Oficina 150, Universidad Nacional, Bogotá, D.C., Colombia.

idrovoaj@hotmail.com

Recibido: 16/02/01; aceptado: 29/06/01 cambios importantes (1). Estudiar el porqué ocurre una epidemia es de importancia crucial para entender a un pueblo y la percepción y el conocimiento que se tiene sobre la salud, la enfermedad y la muerte, máxime cuando la entidad estudiada es una enfermedad emergente o reemergente (2).

La tuberculosis (TBC) es una enfermedad que, al parecer, se encontraba en territorio bogotano desde tiempos prehispánicos. La existencia de factores de riesgo como la agricultura, los asentamientos humanos y la convivencia con animales (3), así como los hallazgos arqueológicos 
compatibles con lesiones tuberculosas son hechos que soportan dicha afirmación (4); sin embargo, su ocurrencia no fue de proporciones mayores como para ser considerada, en términos actuales, un problema de salud pública (5). El comportamiento de la enfermedad durante los períodos de la Conquista y la Colonia no es conocido debido a la poca evidencia arqueológica e histórica disponible. Desde finales del siglo XIX y comienzos del $X X$, la ocurrencia de la enfermedad comenzó a incrementarse rápidamente. Si bien se sabe de la existencia de factores de riesgo para el desarrollo de la enfermedad en aquel período, su relación con la ocurrencia observada no ha sido debidamente documentada.

El presente trabajo describe y analiza, de manera preliminar, el inicio de la epidemia de TBC pulmonar entre 1870 y 1920 y algunos hechos históricos, posiblemente asociados, en el mismo período de tiempo. Este fenómeno epidemiológico, de suma importancia para la historia de la salud pública nacional, aún no ha sido claramente documentado (6). Ocurrió durante un período en el que en la gran mayoría de los países del mundo occidental se observaba un descenso en su incidencia, gracias a las acciones de aislamiento de enfermos y a la erradicación de la TBC bovina (7), y a la aparición de importantes cambios en la infraestructura sanitaria en las décadas siguientes. De esta manera, el comportamiento de la TBC en Bogotá contradecía lo sucedido en otros países o, simplemente, mostraba una etapa previa dentro del proceso de la transición epidemiológica (8).

\section{Tuberculosis en Bogotá}

Conocer con exactitud cuál fue la ocurrencia de TBC en Bogotá entre 1870 y 1920 no es una tarea fácil, debido a la ausencia de unas adecuadas estadísticas. La única fuente conocida por el autor son los registros del Hospital San Juan de Dios (HSJD) de Bogotá, que durante el período en estudio era el principal centro asistencial de la ciudad y lugar de práctica de la Facultad de Medicina de la Universidad Nacional; en el HSJD se atendía, aproximadamente, el $50 \%$ de los casos de TBC de la ciudad (9).

Desde la creación de esta escuela, profundos cambios se sucedieron en la forma de entender la enfermedad y sus causas. Enraizados en la visión anatomopatológica de la medicina francesa, los médicos empezaron a explorar la TBC de manera sistemática y dejaron para la historia descripciones completas de los hallazgos encontrados en las autopsias de los tuberculosos, como la siguiente: "Abierta la cavidad abdominal se nota lo siguiente: falta completa, por regla general, de derrame, $y$ cuando éste existe es en muy pequeña cantidad y jamás de aspecto purulento. El peritoneo contiene frecuentemente tubérculos ya bajo la forma de pequeñas granulaciones amarillas, pequeñas, duras, que á veces pueden ponerse de manifiesto por el tacto, pero que en otros casos es necesario para comprobar su existencia tomar una porción del grande epiplón, por ejemplo, y extenderlo á la luz del sol; ya bajo la forma de tubérculos más voluminosos, de transformación caseosa, amarillos, y en contacto unos con otros y que presentan un aspecto que el doctor Gómez ha comparado muy acertadamente con las producciones malignas. El tubérculo se desarrolla en estas serosas ya sobre el peritoneo parietal y con especialidad en aquel que recubre el intestino, ya en toda la serosa, ligamentos anchos, repliegues, etc." (9).

Los primeros trabajos llamaban la atención acerca de la aparición de los tubérculos en las vísceras blandas abdominales, lo cual contradecía la teoría proveniente de Europa. Esto es claramente expresado por Carlos Fajardo en su tesis Tuberculosis en el Hospital Civil de Bogotá presentada en 1896, en la cual escribe: "En Europa la peritonitis sigue con frecuencia á una pleuresia; en Bogotá se observa lo contrario" (10). Esto no quiere decir que no existiese la TBC pulmonar en Bogotá; cuando ésta aparecía lo hacía generalmente en individuos de las clases más adineradas. No hay que olvidar que incluso Simón Bolívar murió en 1830, al parecer por causa de la TBC (11).

Pese a la alta ocurrencia de tubérculos abdominales, no se encontraron lesiones tuberculosas en los animales para consumo humano. Es así como hacia 1915, Enrique Isaza informaba que la TBC en el ganado de consumo en la ciudad era rara, pese a algunas descripciones que informaban de la presencia de 
tubérculos entre el 10 y el $40 \%$ de los animales sacrificados en el matadero; la afirmación se sustentaba en que dichos tubérculos no eran debidos a Mycobacterium sino a helmintos. "Creemos haberlo alcanzado y contar con un número suficiente de investigaciones para declarar que las lesiones consideradas como tuberculosas por los doctores Restrepo Hernández y Escobar, no son otra cosa que una pseudo-tuberculosis producida por el enquistamiento de una larva que puede corresponder a la familia, o por lo menos a una vecina, de la del esofagostoma de Columbia, descrita por Railliet (...)" (9). Este parásito es Oesophagostomum radiatum (comunicación personal).

Una posible interpretación de esta falta de congruencia de los hallazgos, es que los tubérculos abdominales en humanos, en un primer momento, fueron ocasionados por Mycobacterium bovis y que esta infección otorgó inmunidad frente a Mycobacterium tuberculosis. Durante el mismo período, $O$. radicatum pudo ser prevalente entre los animales para consumo. Con la vigilancia de la calidad de las carnes, la TBC bovina y la infección por $O$. radiatum disminuyeron su ocurrencia, permitiendo la aparición de la epidemia de TBC pulmonar. No hay que olvidar que para esta época apenas se estaban realizando los primeros estudios que tenían por objetivo diferenciar $M$. tuberculosis de otras micobacterias, y que existe una reacción cruzada entre las micobacterias (12) que permite tener inmunidad ante la infección por $M$. tuberculosis cuando hay infección, por ejemplo, por M. bovis.

Este hecho permite suponer que la TBC que primero se presentó en la ciudad fue la causada por $M$. bovis, al cual los habitantes de la ciudad estaban expuestos por el consumo de leche, carne y vísceras de animales infectados, tal cual ha sido observado en la historia de poblaciones de otros países (13). Infortunadamente, no es posible conocer cuál era la magnitud de la ocurrencia de la TBC abdominal debido a que se podía confundir con las 'disenterías' frecuentes en aquella época y que podrían tener como agentes etiológicos principales a virus, bacterias o parásitos.
Posteriormente, hizo su aparición en Bogotá la epidemia de TBC pulmonar. En la figura 1 se puede apreciar la ocurrencia de muerte por TBC en el Hospital San Juan de Dios en el período comprendido entre 1875 y 1914. En esta curva polinomial se pueden apreciar los primeros años de la epidemia de TBC pulmonar, que corresponden a la mayor pendiente en el crecimiento demográfico de la ciudad. La situación de Bogotá era bastante crítica; para intentar darle su dimensión a este problema, se puede comparar su ocurrencia con lo observado en otras ciudades del país (figura 2) y del mundo (figura 3 ) hacia 1921 (14).

Los hallazgos anatomopatológicos empezaron, cada vez más, a seguir los patrones europeos de la enfermedad. Es decir, seguían la teoría unicista de Bayle, Laennec y Louis, según la cual la infección inicial ocurría en los campos pulmonares inferiores, formando el complejo de Ghon; posteriormente, los bacilos se ubicaban en los ápices pulmonares conformando los tubérculos o nódulos de Simon, desde donde se podían diseminar a otros tejidos corporales.

\section{La Bogotá del siglo XIX y comienzos del siglo $\mathrm{XX}$}

Los hechos antes descritos parecen estar íntimamente relacionados con acontecimientos de la historia de Bogotá. Es bien conocida la asociación entre la ocurrencia de TBC y los factores ambientales y sociales. Por tal razón, un análisis de estas condiciones en la ciudad en el

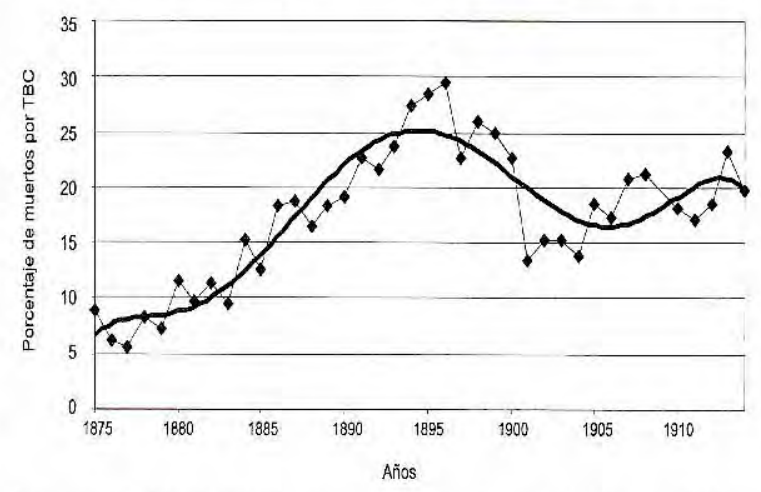

Figura 1. Mortalidad por tuberculosis en el Hospital San Juan de Dios (1875-1914) +.

+ Con base en los datos de la referencia 9. 


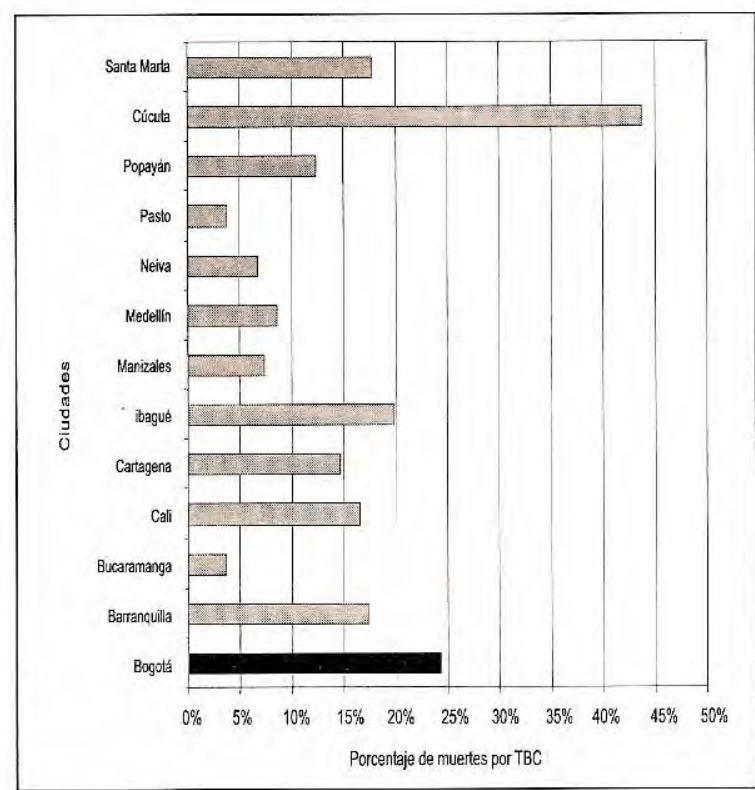

Figura 2. Mortalidad por tuberculosis en varias ciudades de Colombia, $1921^{\dagger}$

† Con base en los datos de la referencia 14.

período inmediatamente previo y durante el inicio de la epidemia de TBC es básico para poder entender el comportamiento de la enfermedad. La información que tenemos de aquella época se basa principalmente en los escritos de viajeros, las descripciones de los primeros médicos formados en la Universidad Nacional y en algunos estudios recientes sobre la historia de la ciudad.

Hacia el año 1800, Bogotá era una ciudad de una gran extensión y una población relativamente escasa, lo que permite suponer un bajo índice de hacinamiento, pues las casas eran bajas y amplias (con múltiples salones, alcobas y patios), y existían numerosos conventos y templos. Esta situación fue cambiando paulatinamente con el paso del tiempo, ya que el número de habitantes de Bogotá fue aumentando hasta llegar, a finales del siglo, a incrementarse en cinco veces, lo que llevó a que el hacinamiento fuera un fenómeno cada vez más frecuente en la ciudad. Esto es evidente, ya que en 1800 la población era de 21.464 y en 1905 llegaba a los 100.000 habitantes, aproximadamente (15). Pese a este incremento, el crecimiento demográfico fue muy lento debido a varios hechos, entre los que sobresalen las

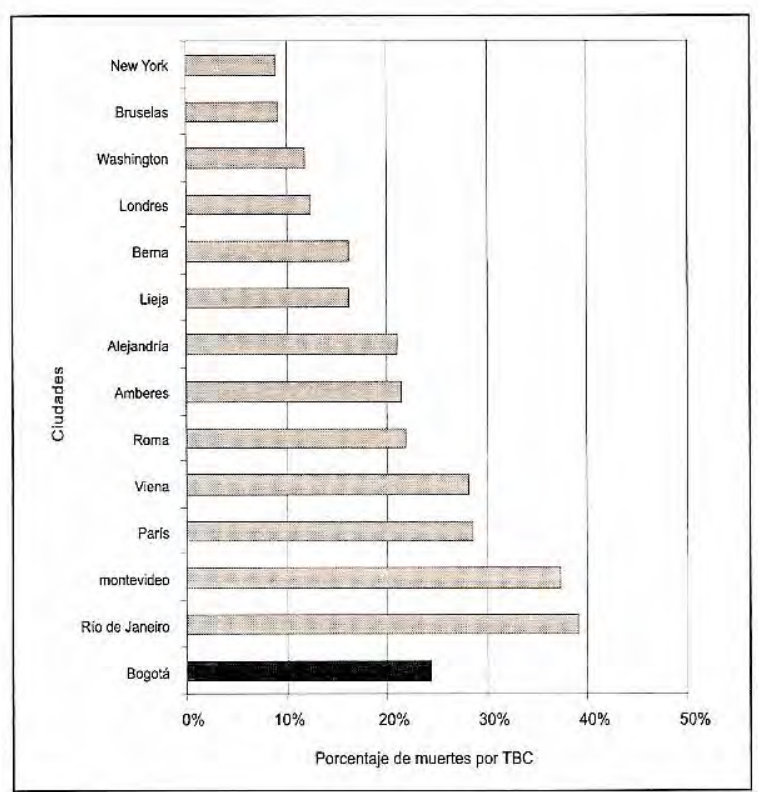

Figura 3. Mortalidad por tuberculosis en varias ciudades del mundo, $1921^{\dagger}$.

† Con base en los datos de la referencia 14.

epidemias de viruela y las guerras civiles, principal causa de mortalidad entre los bogotanos de la época (16). Como se puede apreciar en la figura 4 , el crecimiento demográfico en Bogotá fue relativamente bajo entre el siglo XVII y la primera mitad del XIX; nótese que la pendiente de la curva aumenta después de 1870 y durante los siguientes 50 años, con lo cual se puede evidenciar el inicio de la epidemia de TBC pulmonar en la ciudad. Debido a que el origen de los individuos responsables del incremento de la población de la ciudad se explica más por el concepto de crecimiento vegetativo o natural que por el crecimiento migratorio, es muy probable que los casos presentados en Bogotá se deban a condiciones propias de la ciudad y no de las de la zona rural de donde provenían quienes ingresaron con la población inmigrante (17).

En las viviendas bogotanas también se pueden apreciar los signos del hacinamiento. Mientras al inicio del siglo XIX las casas eran de una sola planta, con el paso del tiempo se fueron construyendo los segundos pisos con el fin de dar albergue a la creciente población. De esta manera, mientras en el piso superior vivían 


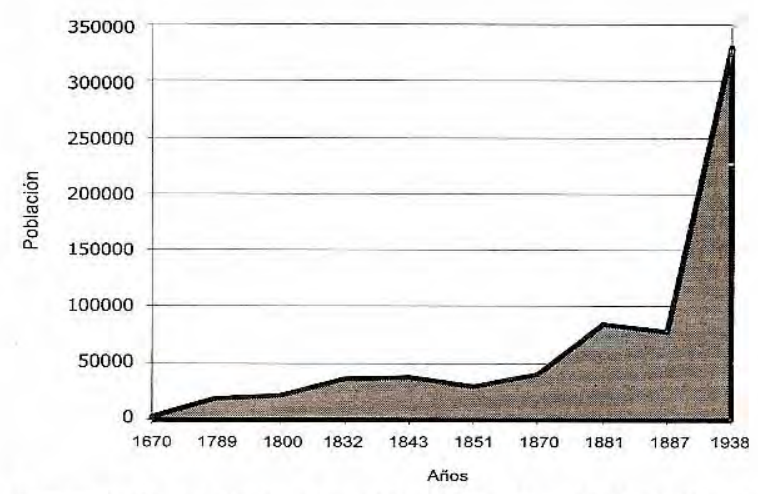

Figura 4. Crecimiento de la población de Bogotá (1670-1938), según los censos de población.

cómodamente los dueños de la casa, el primer piso era arrendado para ser utilizado como local de chicherías o tiendas; en estos mismos lugares vivían los inquilinos en condiciones de grave hacinamiento (18). Carlos Fajardo describe esta situación así: "Bogotá cuenta con 921 casatiendas, 4.799 tiendas y 2.230 ranchos, en los cuales se hacina la población obrera (...). Estos cuartos, lo mismo que las tiendas, la generalidad de las llamadas casatiendas y los ranchos, tienen una sola puerta de acceso á la vía pública, la cual en las casatienda se encuentra obstruída por la exposición de víveres, frutas, etc.; la cubicación escasa, como acabamos de anotar, el piso húmedo, se vive en promiscuidad con animales y cosas; (...) como hemos anotado antes, esa habitación reducida es al mismo tiempo cocina, comedor, dormitorio, criadero de animales, etc." (10).

Respecto a las condiciones sanitarias de la ciudad, se puede afirmar que durante todo el siglo XIX fueron precarias. A manera de ejemplo, Salvador Camacho Roldán describe la ciudad de mediados del siglo con escenas como la siguiente: "Centenares de burros recorrían las calles buscando los restos de las cocinas en los caños, y hacian su mansión principal en la plaza de Bolívar, que era la del mercado" (19). Por su parte, Isaac Holton escribió: "El sábado por la mañana los gallinazos empiezan a revolotear sobre la plaza, especialmente por donde estan los puestos de carne y no dejan un solo desperdicio sin examinar. Después llegan los basureros, que son unos cuantos presidiarios vigilados por dos soldados, barren las hojas que se usaron para envolver, recogen la basura y se acabó el mercado" (20).

Estas escenas no eran más que el resultado de la inexistencia de unos adecuados servicios públicos, en especial los de acueducto, alcantarillado y aseo. Al respecto vale señalar que a comienzos del siglo XIX, en Bogotá solo existían unos pocos acueductos, entre los que sobresalían el de Aguanueva y el de San Victorino. Para finales de siglo, la situación se mantenía casi exacta, hasta cuando en 1886 se firmó el contrato para la construcción del primer acueducto por tubería de hierro, el cual al final terminó realizándose pese a varias trabas administrativas (21). Infortunadamente, este acueducto tampoco pudo satisfacer del preciado líquido a los habitantes de la ciudad, y sólo después de mediados del siglo XX se logró llevar agua potable a la mayoría de los bogotanos. Similar situación le ocurrió al alcantarillado que, aunque se empezó desde 1872, tuvo que sortear múltiples obstáculos durante su larga construcción (18).

La alimentación de la población bogotana era inadecuada y basada en los carbohidratos. El desayuno consistía en un caldo de agua-sal al que a veces se le añadía cilantro o cebolla y un pedazo de pan; la clase alta tomaba chocolate más frecuentemente que los pobres. El almuerzo era, para la mayoría de la población, caldo con papas, mazamorra de harina de maíz con habas o coles; no era frecuente el consumo de carne, pero sí de vísceras, chorizos y longanizas, muchas veces en estado de descomposición (10). La chicha era consumida en grandes cantidades y a cualquier hora del día, principalmente por los habitantes más pobres de la ciudad, hasta llegar a convertirse en el alimento básico de los bogotanos; algunos calculan su consumo en tres litros diarios por persona (22).

La ingestión de carnes y vísceras de animales en mal estado trajo consigo la posibilidad de la existencia y la transmisión de la TBC bovina en Bogotá. El ganado bovino, especialmente el orejinegro de Andalucía, llegó al país desde la época de la Conquista con el fin de asegurar la alimentación de los europeos llegados al Nuevo 
Mundo (23), cuando aún la TBC bovina no había sido controlada. No debe olvidarse que uno de los primeros hallazgos de los médicos de la Universidad Nacional fue la presencia de tubérculos en las carnes y vísceras de dichos animales. Sin embargo, queda como inquietud por resolver en futuros trabajos, cuál fue el microorganismo causante de estas lesiones.

Las condiciones de trabajo tampoco eran las más adecuadas. La mayoría de los bogotanos se dedicaban a labores no industriales y sólo con el paso del tiempo empezarían a ser más frecuentes los operarios de la naciente industria bogotana (24). Entre toda la población, al parecer las mujeres y los niños eran quienes se veían expuestos a un mayor deterioro de su salud; las mujeres realizaban trabajos de alto esfuerzo físico, aún estando en embarazo o lactancia, mientras los niños desde una corta edad laboraban en oficios con igual carga física y horario que los adultos (25).

Todo lo descrito hasta aquí referente a la ciudad resume las características propias de la acelerada urbanización que empezó a experimentar Bogotá. La urbanización es un fenómeno caracterizado por un incremento relativo de la población de las zonas urbanas, que trae consigo cambios en la forma de vivir de sus habitantes, su alimentación y, en general, de los factores ambientales a los cuales se expone la población (26). Un resultado, al parecer inevitable, fue permitir la aparición de enfermedades infecciosas como la TBC.

\section{Respuesta social a la epidemia}

Los profesionales de la medicina, que durante el período estudiado eran quienes empezaban a liderar el manejo de las epidemias y las enfermedades en general (1), no dudaron un momento en sugerir las políticas para evitar la infección y controlar y tratar la enfermedad. Algunas de estas recomendaciones, vistas desde la actualidad, tenían un fuerte sustento científico, mientras que otras podrían pasar por absurdas.

Las recomendaciones de carácter sanitarista más repetitivas eran: 1) mejorar el aseo de la ciudad y las condiciones de las viviendas; 2) evitar el consumo de la chicha, así como la preparación de alimentos en las chicherías; 3 ) impedir el lavado de ropa en los ríos que atravesaban la ciudad; 4) crear un hospital y dispensario para tuberculosos, y 5) implementar la vigilancia de la calidad de las carnes para consumo humano $(9,10)$. Esta última medida fue adoptada y un inspector comenzó a vigilar las carnes desde abril de 1886 (27).

Las sugerencias también incluían rígidas pautas de conducta en los espacios públicos como escuelas, talleres, cuarteles, iglesias, hoteles, restaurantes, cantinas, chicherías, vehículos, teatros, salones, bancos, calles, plazas y lavaderos, entre otros (9). Para la vida privada se recomendaba extremar las condiciones de aseo mejorando la ventilación, aislar los elementos del enfermo e, incluso, evitar los besos (9), la lactancia materna, las relaciones sexuales y el matrimonio "no solamente porque agravaría su estado de salud por los excesos que impone el primer periodo (...), sino por lo que es más grave aún, procrearía hijos débiles raquíticos, que, si no están tuberculosos desde su nacimiento, quedarán en circunstancias favorables para, tarde ó temprano, ser presas de la terrible enfermedad y esparcir á su turno el contagio" (25).

\section{Conclusión}

Durante los años comprendidos entre 1870 y 1920 se inició en Bogotá la epidemia de TBC pulmonar que posteriormente se transformó en endemia. Con el inicio de los estudios anatomopatológicos en medicina hubo confusión entre las lesiones de TBC abdominal por $M$. bovis y las ocasionadas por $O$. radicatum, debido a que en su ocurrencia convergió la fase inicial de la epidemia de TBC pulmonar. El diagnóstico diferencial sólo pudo lograrse con ayuda de la anatomía patológica, iniciada en la Facultad de Medicina de la Universidad Nacional. De esta manera, la 'medicina bacteriológica' (1), cuya labor se desarrollaba en el anfiteatro, exploró el cuerpo humano y así se introdujo en la intimidad de la ciudad y de sus habitantes (28).

Los hechos revisados en este trabajo sugieren que el incremento en la ocurrencia de TBC pulmonar durante el período estudiado está íntimamente relacionado con el rápido proceso de urbanización (29) de la capital colombiana, de manera similar al fenómeno ocurrido en Africa (30). Una inquietud 
no resuelta en este trabajo es si los individuos infectados con $M$. bovis provenían de zonas rurales, donde estaban sus hospederos naturales, y si de esta manera llegó la micobacteria a Bogotá con un efecto protector frente al bacilo de Koch. Teniendo en cuenta esta consideración, y dado que para algunos historiadores de la medicina la causa social de que se incluyese la TBC en el perfil de enfermedades infecciosas del país es la asociación infección-desnutrición propiciada por unas condiciones laborales precarias y una distribución desigual de los terrenos agrícolas convertidos en dehesas ganaderas monopólicas, lo cual trajo como resultado el empobrecimiento de la mayor parte de la población (31), se puede afirmar que las causas de la epidemia se deben a condiciones sociales, económicas y ecológicas que confluyeron en una compleja red causal (32) para permitir su desarrollo. Similares situaciones a la aquí presentada se han sucedido en otras regiones del mundo como Brasil (33).

La respuesta, similar a la que se proponía para combatir la lepra, se limitó a medidas que no incluyeran cambios sociales radicales (34), como vigilar las carnes para consumo y empezar una guerra contra el popular consumo de la chicha (22). En definitiva, el inicio de la epidemia de TBC pulmonar de finales del siglo XIX y comienzos del $X X$ no es más que un claro ejemplo de lo que ha sido denominado como la 'patogenicidad del progreso' (35), en la cual la relación hombreambiente se ve alterada por la forma en que el hombre modifica su entorno y favorece la aparición o incremento en la ocurrencia de enfermedades.

\section{Agradecimientos}

A Jimmy Vargas de la Facultad de Medicina Veterinaria y Zootecnia de la Universidad Nacional de Colombia por su ayuda en la identificación de $O$. radiatum y a Juan Carlos Eslava y Mauricio Restrepo del Departamento de Salud Pública y Tropical de la Facultad de Medicina de la Universidad Nacional de Colombia por sus valiosas sugerencias al documento final.

\section{Referencias}

1. Obregón D. Sobre epidemias, endemias y epizootias: algunos aspectos del desarrollo de la bacteriología en Colombia. Biomédica 1998;18:110-21.
2. Mayer JD. Geography, ecology, and emerging infectious diseases. Soc Sci Med 2000;50:937-52.

3. Idrovo AJ. Tuberculosis prehispánica en muiscas de la sabana de Bogotá. Rev Fac Med UN Col 1997;45:50-4.

4. Rodríguez JV, Etxeberria F. La tuberculosis en Colombia prehispánica. Bol Asoc Esp Paleopatol 1998; 9:8-17.

5. Sotomayor HA. Arqueomedicina de Colombia prehispánica. Santafé de Bogotá: Cafam; 1992. p.21.

6. Romero A. Historia de la salud pública y la epidemiología en Colombia. Medellín: Oficina Sanitaria Panamericana Facultad Nacional de Salud Pública/Sociedad Colombiana de Epidemiología; 1999.

7. Fairchild AL, Oppenheimer GM. Public health nihilism vs. pragmatism: history, politics, and the control of tuberculosis. Am J Public Health 1998;88:1105-17.

8. Frenk J, Frejka T, Bobadilla JL, Stern C, Lozano R, Sepúlveda $\mathbf{J}$, et al. La transición epidemiológica en América Latina. Bol Of Sanit Panam 1991;111:485-96.

9. Isaza E. La tuberculosis en Bogotá - Profilaxis (tesis). Bogotá: Universidad Nacional y Arboleda \& Valencia; 1915. p.1-90.

10. Fajardo C. Tuberculosis en el Hospital Civil de Bogotá (tesis). Bogotá: Universidad Nacional y Samper Matiz; 1896.

11. Serpa F. La muerte de Bolívar. En: Páginas de historia de la medicina. Bogotá: Laboratorios Roche; 1992. p.70-9.

12. Lietman T, Porco T, Blower S. Leprosy and tuberculosis: the epidemiological consequences of cross-immunity. Am J Public Health 1997;87:1923-7.

13. Bates JH, Stead WW. The history of tuberculosis as a global epidemic. Med Clin North Am 1993;77:1205-17.

14. Trujillo C. Contribución al estudio del problema de la tuberculosis en Bogotá (tesis). Bogotá: Universidad Nacional; 1923.

15. Fundación Misión Colombia. Vida cotidiana y cultura. Aspectos demográficos. En: Historia de Bogotá. Tomo IISiglo XIX. Bogotá: Salvat-Villegas editores; 1989. p.9-56.

16. Fundación Misión Colombia. El panorama urbano. En: Historia de Bogotá. Tomo I - Siglo XIX. Bogotá: SalvatVillegas editores; 1989. p.19-36.

17. González A. Conceptos y técnicas básicas de análisis demográfico. Bogotá: Universidad Externado de Colombia; 1998. p.1-123.

18. Iriarte A. Breve historia de Bogotá. Bogotá: Editorial Oveja Negra; 1988. p. 90.

19. Camacho S. Mis memorias. Bogotá; 1894. p.98-9.

20. Holton IF. La Nueva Granada: veinte meses en los Andes. Bogotá: Banco de la República; 1981. p.187. 
21. Empresa de Acueducto y Alcantarillado de Bogotá, EAAB. El agua en la historia de una ciudad. Vol. 1. Bogotá: EAAB; 1988. p.185-204.

22. Llano MC, Campuzano M. La chicha, una bebida fermentada a través de la historia. Bogotá: Instituto Colombiano de Antropología-CEREC; 1994. p.81.

23. Gómez A. De las dehesas de Andalucía a hoy. En: La ganadería en América Latina. Colombia. Bogotá: Tercer Mundo; 1976. p.125-7.

24. Arturo J, Muñoz J. La clase obrera de Bogotá. Apuntes para una periodización de su historia. Maguaré Rev Depto Antropol UN Col 1981;1:99-158.

25. Solano N. Tuberculosis en Colombia. Estudio sobre su etiología y profilaxis (tesis). Bogotá: Universidad Nacional; 1909.

26. Phillips DR. Urbanization and human health. Parasitology 1993;106(Suppl.):S93-107.

27. Anónimo. Tesis presentada por Antonio María Olaechea en el examen general de veterinaria para optar el título de médico en este ramo. Anales de Instrucción Pública 1890;17(96-97):262-71.
28. Foucault M. El nacimiento de la clínica. México: Siglo Veintiuno editores; 1979. p.244.

29. Yach D, Mathews C, Buch E. Urbanisation and health: methodological difficulties in undertaking epidemiological research in developing countries. Soc Sci Med 1990; 31:507-14.

30. Hunter JM, Thomas MO. Hypothesis of leprosy, tuberculosis, and urbanization in Africa. Soc Sci Med 1984;19:27-57.

31. Romero A. Historia de la medicina en Colombia. Siglo XIX. Medellín: Universidad de Antioquia-Colciencias; 1996. p.209.

32. Krieger N. Epidemiology and the web of causation: Has anyone seen the spider? Soc Sci Med 1994;39:887-93.

33. Gonçalves H. A tuberculose ao longo dos tempos. Hist Cienc Saúde Manguinhos 2000;7:303-25.

34. Obregón D. Lepra e investigación bacteriológica en Colombia: los casos de Carrasquilla y de Lleras. Biomédica 2000;20:181-9.

35. Galdston I. The pathogenicity of progress. Med Hist 1965;9:127-32. 